University for Business and Technology in Kosovo

UBT Knowledge Center

UBT International Conference

2018 UBT International Conference

Oct 27th, 1:30 PM - 3:00 PM

\title{
Trial of young adults and sanctions against them
}

\author{
Albulena U. Ukimeraj \\ University for Business and Technology, albulena.ukimeraj@ubt-uni.net
}

Follow this and additional works at: https://knowledgecenter.ubt-uni.net/conference

Part of the Law Commons

\section{Recommended Citation}

Ukimeraj, Albulena U., "Trial of young adults and sanctions against them" (2018). UBT International Conference. 273.

https://knowledgecenter.ubt-uni.net/conference/2018/all-events/273

This Event is brought to you for free and open access by the Publication and Journals at UBT Knowledge Center. It has been accepted for inclusion in UBT International Conference by an authorized administrator of UBT Knowledge Center. For more information, please contact knowledge.center@ubt-uni.net. 


\title{
Trial of young adults and sanctions against them
}

\author{
Albulena U. Ukimeraj \\ UBT - Higher Education Institution, Kalabria, 10000 p.n., Prishtina, Kosovo
} The juvenile delinquency issue is also regulated by the Kosovo legislation, respectively with the
Juvenile Justice Code. This Code, also addresses the issue of adjudication of young adults. To
these category, a special and more favorable status is been recognized comparing to the older
persons in criminal procedure conducted against them, because of their different personality
features and their different reaction in specific situations. The possibility to pronounce lenient
sanctions on the young adults is also well covered by other social sciences such as criminology,
psychology, criminal law, criminal procedure law and it is claimed that the purpose of criminal
sanctions in some of these cases will be better achieved with measures and lighter penalties. The
real reason to analyze this topic lies in the fact that this category (major young persons, 18 to 21
years) is a more specific category, regulated by the JJC, but taking into account the criminal
offenses and the nature of their commission, with perpetrators 18 to 21 years, there is already an
attitude from the Supreme Court of Kosovo that in certain cases when it comes to particularly
serious criminal offenses, the provisions of the Criminal Code of Kosovo should be pronounced
rather than the measures and penalties for juveniles as provided by the Code of Juvenile Justice.
This paper will analyze the juvenile delinquency, legal framework of the Republic of Kosovo,
with particular emphasis on the category of young adults and sanctions against them, and
conclusions are provided at the end of this paper.
Keywords: juvenile delinquency; young adults; Juvenile Justice Code; Criminal offenses, Law etc.

\section{Introduction}

The term delinquency (Deviation) derives from the Latin word "deliquare" which has a very broad meaning1. This term generally means the repeated expressions, behaviors and actions of minors that conflict with the morals, habits, and laws of the environment in which they live. The juvenile criminality as illegal behavior represents a complicated phenomenon, which requires full knowledge of the causes and circumstances of its occurrence. 2 Delinquency has always existed and has appeared somewhere less and somewhere more, depending on the changes in society and the environment in which young people have lived. Delinquent is a person who has exerted repeated deviant behavior, who commits criminal acts, thus violating applicable legal norms. This kind of (delinquent) behavior of young people does not appear immediately, but it starts to emerge in a mild way and asocial behavior begins with adolescence 11-14 years old. Today, in modern times we have a high percentage of juvenile involvement in criminality, and to a lesser extent, juvenile delinquency is a phenomenon in all countries, whether developed or underdeveloped. Juvenile participation in general criminality already accounts for $10 \%$ - up to $30 \%$ or more. Thus in France and Germany, juvenile participation in general criminality is over 30\%.3 Many countries already regulated juvenile delinquency and criminality by juvenile specific laws and codes. Even our country, the Republic of Kosovo, has gone through several stages regarding the treatment of juvenile delinquency, adopting provisions that are approximate with other countries, regulating this issue with the Code of Juvenile Justice, adopted on July 08, 
20104. This code also addresses the category of young adults (18-21 years), which is also the focus of this paper.

\section{International Standards on Juvenile Justice}

The key international instruments for children's rights are listed ${ }^{5}$ :

- UN Convention on the Rights of the Child;

- United Nations Standard Minimum Rules for the Administration of Juvenile Justice ("The Beijing Rules");

- United Nations Guidelines for the Prevention of Juvenile Delinquency (Riyadh Guidelines)

- Resolution 2005/20 Guidelines on Justice in Matters Involving Child Victims and Witnesses of Crime;

- European Convention on Human Rights;

- Protocol no. 12 of the European Convention for the Protection of Human Rights and Fundamental Freedoms: General prohibition of discrimination;

- The Convention against Torture and Other Cruel, Inhuman or Degrading Treatment or Punishment

- The European Convention for the Prevention of Torture and Inhuman or Degrading Treatment or Punishment;

- UN Convention on the Rights of the Child - General Comment no. 10 (2007) on "Children's Rights in Juvenile Justice";

- UN Convention on the Rights of the Child - General Comment No.12 (2009) on "The right of the child to be heard";

- Council of Europe guidelines on child-friendly justice.

- International Covenant on Civil and Political Rights;

- Universal Declaration of Human Rights:

\section{Forms of Delinquency and Types of Crimes}

The ways of displaying social behaviors are as in juveniles, manifested by stubbornness, insults and swearing, batter, disobedience and impatience, theft, abandoning home, school drop-outs, etc. So if at this age no proper measures are taken to eliminate such behavior, they will steadily increase and the child will gradually assume the epithet of the "delinquent child".6 Most juveniles are involved in criminality in the commission of these types of offenses: Offenses against property; Violence; Drug consumption and trafficking; Prostitution etc. "Juvenile gangs" - whose criminal activity is mainly associated with the use of high-level violence. "Political Terrorism" on national and religious grounds.

\section{The position of the juvenile during the history of mankind}

Human society during its historic development has emphasized various forms of treatment of minors. What you may notice throughout the developmental stages of society is that juveniles have received special treatment, considering that they have not yet reached biopsychic maturity. In Roman law, up to the age of 7 years, 7 years old... No criminal liability ... After 7 years of age, only exclusively applied. (Age 10 - unlimited criminal liability)... - mitigating circumstances. In the early Middle Ages - juvenile delinquency was considered accidental and unintentional, and the tendency was for juveniles to have no liability ... or for elderly/their caregivers to pay for damages caused by them.

Thus, old Chinese law recognized three stages of juvenile criminal liability: a) the juvenile under the age of seven was completely exempt from punishment; b) for minors 7-10 years old the proposal of pardon from the emperor was foreseen, and c) the minor who committed the criminal offense punished by death penalty faced fine only. In ancient Greece juvenile criminal offenses were treated as inflicted damages, and if children were convicted, they did so more to satisfy the 
victim's family demands rather than to have the child suffer for the offense. ${ }^{7}$ Criminal liability of juveniles: XVIII century; Cesario Becdaria - Applied "Discerminento" institute - criterion for Punishment of minors - 12-14 years old... Criminal Code of Toscana... 1786 (The first code for the provision of juvenile sentences)

French Criminal Code... 1791 (special criminal law measures - when minors are supposed to understand their actions). XX Century - Increasing number of special measures against minors... Persons as of the age of 18 are considered adults... Following the introduction of educational measures as special types of criminal sanctions targeting juvenile offenders, special juvenile courts have emerged... First Court - Chicago... 1899

\section{Categorization}

Based on the Juvenile Justice Code, the categorization of juveniles by age is as follows: Child a person who is under the age of eighteen (18) years. Minor - a person who is between the ages of fourteen (14) and eighteen (18) years. Young juvenile- a person who is between the ages of fourteen (14) years and sixteen (16) years. Adult juvenile- a person who is between the ages of sixteen (16) years and eighteen (18) years. Young adult- a person who is between the ages of eighteen (18) years and twenty-one (21) years.

In cases where persons of the age of 18 commit criminal offenses, they may be subject to all types of criminal sanctions provided for by criminal legislation, as when they turn 18 years of age, they are considered criminally liable.

However, based on scientific knowledge, there is a possibility that a person, even though he or she has reached the age of 18, may not reach the appropriate biopsychic and social development and maturity until the age of twenty-one. Consequently, persons between the ages of 18 and 21 in criminal law are called young adults, therefore this lead to the Juvenile Justice Code providing for criminal sanctions against juveniles of this age-range who have committed a crime.

In order to be able to impose juvenile criminal penalties against a young adult, Article 11 of the Juvenile Justice Code provided that such person at the time of trial had not reached the age of 21 , and that the court taking into account the circumstances in which the offense has been committed, the expert's opinion on the psychological development of the young adult and his or her best interest, and the judgment that these types of measures or punishments will achieve the purpose through imprisonment sentence. The imposition of a diversity measure, educational measure or juvenile punishment against persons who have committed the offense as young adults is optional. Consequently, the Juvenile Justice Code leaves it up to the court to decide, as the case may be, upon discretion, to impose a prison sentence or a measure of diversity, or an educational measure or imprisonment against the juvenile offender who has the capacity of a young adult. When adjudicating, the court must consider the severity and type of the offense, the circumstances in which the offense was committed, the level of psychological development of the young adult determined in the opinion of the relevant expert, the motives for the offense and all other subjective and objective circumstances justifying the imposition of the relevant measure or sentence.

However, there is a noticeable contradiction between the Juvenile Code and the Criminal Procedure Code, especially in cases involving young adult defendants (defendants between 1821 years old). The Criminal Procedure Code indicates "[...] young adult maturity assessment [...]" without specifying how the assessment will be conducted and by whom. 8

A juvenile perpetrator of a criminal offense is usually sentenced before turning 18 years of age. However, rare cases can occur when the person who has committed the crime at the minor age is sentenced to a criminal sanction after turning 18 . Such a situation may arise because the criminal offense was later discovered or because the juvenile offender during the criminal proceedings 
reached the age of 18. In such cases the question arises as to what kind of criminal sanction the court may sentence the adult person for the criminal offense committed while being a minor. This issue has been resolved in principle by the Juvenile Justice Code. Adult persons who have committed criminal offenses as minors, depending on whether they are minors under the age of 16 or have reached the age of 16 , are subject to diversity measures, educational measures or punishments prescribed for minors (Article 9 and 10). The fact that the criminal offense has not been timely disclosed, or the criminal procedure has been delayed, must not harm the perpetrator, resulting in imposition of more severe criminal sanctions, provided for adult persons. Therefore, the court may not impose the criminal sanctions foreseen for adults against the adult offender who committed the crime as a minor.

An adult who has committed the offense between the age of 14 and 16, while a young juvenile, pursuant to paragraphs 1 and 2 of Article 9 of the Juvenile Justice Code may be tried for that offense only when the person has not reached the age of 21 and if the offense is punishable by imprisonment of more than 5 years.

In these cases, the courts have only limited options available to impose criminal sanctions on such persons. In fact, the court is likely to impose on such a person only one of the institutional educational measures. Which institutional educational measure the court will issue depends on the circumstances that characterize the case, the type and severity of the offense, the age of the juvenile, the level of psychological development, the character and inclinations of the juvenile, the motives for the offense, the environment and the circumstances of his life, the conduct of the offender and the purpose to be achieved by the imposition of an institutional educational measure. In cases when an adult is convicted of an offense committed as an adult juvenile, the Juvenile Justice Code does not impose any restrictions on the age. Therefore the person can be tried at any age, providing that the statutory limitation for prosecution did not pass. Consequently, pursuant to Article 10 of the Juvenile Justice Code, adult persons who have committed offenses between the ages of 16 and 18 may be imposed any of the diversity measures, educational measures and penalties for juveniles, even exceptionally imprisonment or suspended sentence if the conditions for their imposition are met. Diversity measure, educational measure, juvenile or prison sentence, suspended sentence will be imposed depending on the severity of the offense, the time elapsed since commission, the conduct of the offender, and the purpose to be achieved by the application of the measure or sentence.

When it comes to perpetrators up to the age of 18 , it is known that the provisions of the JJC apply, but the problem is when the perpetrators are 18-21 who are otherwise known as adult perpetrators, the question arises as to which category of criminal procedure should be applied and which measures, penalties may be imposed on young adults as perpetrators?

Given the persistent dilemma, the Basic Court in Mitrovica requested legal opinion from the Supreme Court.

The legal opinion given by the Supreme Court states that: Against a young adult who has committed a criminal offense as a young adult, the procedure under the JJC may be applied if the court finds that the intention would be achieved by imposing imprisonment, or by imposing a measure or sentence, taking into account the circumstances under which the offense was committed, the expert's opinion on the psychological development of the young adult and his best interest, otherwise the provisions of the CPCK shall apply in all respects.

Article 4. The JJC which has created dilemmas in practice states: The provisions of the present Code shall apply to any person charged with a criminal offence committed as a minor, regardless of his or her age at the time when proceedings are instituted (par. 1),

The provisions of the present Code shall apply to any person charged with a criminal offence committed as a young adult (par. 2).

Procedural provisions by the JJC may apply to this category of perpetrators ${ }^{9}$ (although the law did not use the expression 'may') if the court considers that the purpose would be achieved by imposing the measure or sentence, taking into account the circumstances in which the offense 
was committed, the expert's opinion regarding the psychological development of the adult and his best interest.

Thus, the application of the provisions of the JJC to this category of perpetrators is a matter of discretion of the court and not a necessity, although unfortunately the legislator in the construction of Article 4. par.2. of the JJC has omitted the use of 'may', as previously provided by Article 3 of the Juvenile Criminal Law of Kosovo ${ }^{10}$, which under paragraph 2 provides: When provided by this Law, the provisions of this Law shall apply to any person charged with a criminal offense as a young adult and the law provides for this in Article 10.

The criminal law of SFRY 3 regulated these situations as follows: Special provisions pertaining to juvenile perpetrators of criminal offenses shall apply under the conditions provided for in the provisions of this section also to adult persons when adjudicated for criminal offenses committed by a juvenile, and exclusively to persons who have committed a criminal offense as young adults. JJC provides that in court proceedings conducted against a young adult who committed an offense as young adult, the court may impose a measure or punishment in accordance with Article 12, if it determines that the objective that would be achieved by imposing a term of imprisonment would also be achieved by imposing the measure or punishment, considering the circumstances in which the criminal offence was committed, the expert opinion in relation to the psychological development of the young adult and his or her best interest, 11 and this wording clearly indicates that punishment under Article 40 of the CCK may also be sentenced. Then the article 41 of the CCK states that the sentence of life-long imprisonment cannot be imposed on a young adult, which leads to the conclusion that imprisonment may be imposed.

All these facts stated above lead to the undisputed conclusion that the young adult, for the criminal offenses committed as a young adult, the provisions of the CPCK apply in principle, the application of the provisions of the JJC to this category of perpetrators is a discretionary matter of the court, not a must.12

\section{The system of criminal sanctions against minors in French criminal legislation}

In France, criminal penalties for juveniles are foreseen in the French Penal Code. Article 122-8 of this Code sets the age for criminal liability. The solutions provided in this article stipulate that a person under 10 years of age shall not be criminally liable, although stipulating that appropriate educational measures may be applied to them. This solution applies in principle to persons aged 10-13 years. Consequently, the issue of criminal sanctions on juveniles in France is regulated in more detail by the French Juvenile Justice Code.

Under these two Codes, juveniles who commit offenses from the age of 13 to 16 years may be fined and may be remanded in custody as a measure of securing their presence in criminal proceedings. Juveniles aged 16-18 may also be sentenced to juvenile imprisonment. Notwithstanding the prescribed solution, the Codes in question make it clear that juveniles between the ages of 13 and 18 should be given priority in educational measures when imposing criminal sanctions. The competent court shall impose the sentence of imprisonment upon the juvenile when it finds that he is criminally liable and has committed a serious criminal offense, and in aggravating circumstances. In cases where the offense was committed in particularly mitigating circumstances, according to the French legislator, the sentence may be imposed at the half range of the provided punishment for the offense under trial. In imposing this sentence, the court shall take into account the age of the juvenile, psychological maturity, character and abilities, education, environment and life circumstances, the reasons and causes for the commission of the criminal offense, prior conduct, behavior after committing a criminal offense, etc. 
As a result, among the solutions provided by the Criminal Code respectively the Juvenile Justice Code of France and those set out in the Juvenile Justice Code of Kosovo and the relevant legislation of the Republic of Albania, Macedonia, Serbia, Croatia, Afghanistan and Romania, there are obvious differences with regard to juvenile criminal sanctions. This Code does not foresee diversity measures at all; it does not foresee the measure of increased supervision by the other family, the educational measure of sending to the education institution. Also, this Code has not made a detailed provision of the criminal sanctions foreseen in its solutions.

\section{The system of criminal sanctions against minors in Albanian criminal legislation}

Criminal sanctions for juveniles in the Republic of Albania are currently stipulated in the Criminal Code of 1995. This Code provides that juvenile offenders may be subject to educational measures and imprisonment for juveniles. Consequently, within the framework of educational measures, the Criminal Code of the Republic of Albania, in point 1, paragraph 3 of Article 46 has provided for the possibility of imposing only one educational measure on juvenile perpetrators of criminal offenses, and the placement of a juvenile in an educational institution. According to the solution provided for in paragraph 1 of this article, educational measures may be imposed on juveniles in cases where they are excluded from punishment or who have no criminal liability due to their age.

Indeed, under the provisions of this Code, minors who have not reached the age of 14 years cannot be prosecuted and punished for the crimes they have committed, regardless of their degree of social danger. However, juveniles who have not reached the age of 16 may not be prosecuted or convicted for criminal offenses.

\section{The system of criminal sanctions against minors in Macedonian criminal legislation}

Criminal sanctions on juveniles in the Republic of Macedonia are defined by the Law on Juvenile Rights which has addressed specific solutions, which present an exception to the solutions applied to adult offenders. According to this law, the following types of criminal sanctions may be imposed on juveniles: disciplinary measures, educational measures and punishments. The purpose of criminal sanctions against juveniles is to provide protection and assistance to juveniles.

Macedonian lawmakers have envisaged the possibility of imposing penalties on juvenile offenders (16-18 years old). The penalties that can be imposed on juveniles under Article 43 of the Law on Juvenile Rights are: imprisonment for juveniles, fine, driving ban and expulsion of foreigners from the country.

The juvenile imprisonment sentence may be imposed on juvenile adult offenders who have criminal liability, have committed a crime punishable by imprisonment of at least five years and have committed the offense in particularly serious circumstances, and when it is considered that imposition of educational measures would not be reasonable. The term of imprisonment for juveniles ranges from one to 10 years. When imposing imprisonment sentence against a juvenile, the court must consider all the aggravating and mitigating circumstances of the present case. The fine may be imposed only on the juvenile adult, who has criminal liability, who has committed the criminal offense for the purpose of gaining certain property interests, and when committed a criminal offense punishable with imprisonment of at least 3 years. The fine shall be imposed on 
daily rates which may not be less than 1 and not more than 120 daily rates. The characteristic of this type of punishment is that if the juvenile does not pay the fine, the court will replace the fine with the community service work. In these cases, a daily fine is replaced by 3 hours of work, in which case the total number of hours of service work may not exceed 100 hours.

\section{The system of criminal sanctions against minors in Serbian criminal legislation}

Criminal sanctions on juveniles in the Republic of Serbia are defined by the Law on Juvenile Offenders and the Criminal Protection of Juveniles which has addressed specific solutions, which are an exception to the solutions applicable to adult offenders. According to this law, the following types of criminal sanctions may be imposed on juveniles: disciplinary measures, educational measures and punishments. The purpose of criminal sanctions against juveniles is to provide protection and assistance to juveniles.

As a disciplinary measure that may be imposed on juvenile offenders, this Law provides for special reprimands and obligations.

Serb lawmakers have envisaged the possibility of imposing penalties on juvenile offenders (1618 years old). Thus, pursuant to Article 29 of the Law on Juvenile Offenders and the Criminal Legal Protection of Juveniles against Juveniles, imprisonment sentence may be imposed on juvenile. The juvenile imprisonment sentence may be imposed on adult juvenile offenders who have criminal liability, have committed a crime punishable by imprisonment of at least 5 years and have committed the offense in particularly serious circumstances, and when it is considered that imposition of educational measures would not be reasonable. The duration of imprisonment for juveniles ranges from 6 months to 10 years. When imposing imprisonment sentence against a juvenile, the court must consider all the aggravating and mitigating circumstances of the present case.

\section{The system of criminal sanctions against minors in Croatian criminal legislation}

Criminal sanctions against juveniles in the Republic of Croatia are set out in the Criminal Code, which also establishes criminal sanctions for adult persons. According to this Code, the following types of criminal sanctions may be imposed on juveniles: disciplinary measures, educational measures and punishments. The purpose of criminal sanctions against juveniles is to provide protection and assistance to juveniles.

Croatian lawmakers have envisaged the possibility of imposing penalties on juvenile offenders (16-18 years old). The punishment that can be imposed on juveniles under Article 24 of the Criminal Code is the sentence of juvenile imprisonment. The juvenile imprisonment sentence may be imposed on adult juvenile offenders who have criminal liability, have committed a crime punishable by imprisonment of at least 5 years and have committed the offense in particularly serious circumstances, and when it is considered that imposition of educational measures would not be reasonable. The duration of imprisonment for juveniles ranges from 6 months to 10 years. When imposing imprisonment sentence against a juvenile, the court must Considerations all the aggravating and mitigating circumstances of the present case. 


\section{The system of criminal sanctions against minors in Afghani criminal legislation}

In Afghanistan, criminal penalties for juveniles are foreseen in the Juvenile Code. This country has also established juvenile courts within each province. The Code regulates the specifics, while legal solutions that apply to adults also apply for juveniles for anything that was not regulated by this Code. Article 10 of this Code sets the age for criminal liability. The solutions provided in this article stipulate that a person under 12 years of age shall not be criminally liable, although stipulating concrete measures for persons of the age of 7-12.

Statistical data of the Kosovo Police during 2015, 2016, 2017 and 2018 show that the number of suspected persons, but also the criminal offenses involving juvenile adult offenders, is changing. Thus the offenses committed by this category of delinquents are:

1. Accidents - the data show a decreasing number of persons involved in accidents from 2015 to 2018

1500

$2015-8271000$

$2016-998500$

$2017-9660$

Accidents

$2018-817$

2. Disruption of public order - data show decreasing number of persons involved in the commission of this criminal offense from 2015 to 2018

300

$2015-263$

$2016-230$

$2017-2090$

Disruption of public order

$2018-158$

3. Light bodily injury - data show decreasing number of persons involved in the commission of this criminal offense from 2015 to 2018 .

0

4. Unauthorized possession of narcotic drugs, psychotropic substances or analogues - show increasing number of suspected persons in terms of involvement in such offenses.

200

100

600

Light bodily injury

$2015-517400$

$2016-559200$

$2017-496$

$2018-428$

400

Unauthorized possession of narcotic drugs, psychotropic substances or analogues 200 2015 - 99

2016 - 185 
5. Theft - data show decreasing number of persons involved in the commission of this criminal offense from 2015 to 2018.

300

Theft

6. Destruction or damage to property - data show decreasing number of persons involved in the commission of this criminal offense from 2015 to 2018.

7. Unauthorized ownership, control or possession of weapons - data show decreasing number of persons involved in the commission of this criminal offense from 2015 to 2018 .

8. Endangering public traffic - show increasing number of suspected persons in terms of involvement in such offenses.

$2015-238200$

$2016-238100$

$2017-1770$

$2018-147$

200150

$2015-185$

100

$2016-189$

50

2017 - 108 0Destruction or damage to property

$2018-69$

200150

50

OUnauthorized ownership, control or

possession of weapons

$2015-187100$

$2016-149$

$2017-156$

$2018-160$

600

400

2015 - 340

2016 - 401200

2017 - 485

0

$2018-455$

Endangering public traffic

11 


\section{Conclusions}

- Given the very important and indispensable role of all actors in juvenile court proceedings, it is imperative that these professionals have in-depth knowledge of juvenile rights, international instruments providing for these rights and their application in practice

- Continuous professional development and strengthening of the capacities of the entities conducting juvenile proceedings. Judges, Prosecutors, Attorneys at Law and other professionals should specialize in juvenile justice.

- The criminal proceedings against juveniles should focus on preventing injury to the juvenile from adequate treatment as its primary goal. This should result in having the minor return to society, as a reintegrated and re-educated person.

- When initiating juvenile proceedings, the following question should be asked: What is the interest of the minor in the procedure? The best interest of the minor should always be considered;

\section{References}

1. Analysis: "Juvenile Justice in Albania" 2015, UNICEF - Tirana, Albania p. 13

2. Juvenile Justice Code, no. 03/L-193, 08 July 2010

3. Constitution of the Republic of Kosovo,

4. The Constitution of the Republic of Albania, adopted by the law no. 8417, dated 21.10.1998 of the People's Assembly. Adopted by referendum on 22.11.1998; Promulgated by Decree no. 2260, dated 28.11.1998 of the President of the Republic, Rexhep Mejdani; Amended by the Law no. 9675, dated 13.1.2007; Amended by the Law no. 9904, dated 21.4.2008; Amended by the Law no. 88/2012 (dated 18.09.2012)

5. Universal Declaration of Human Rights;

6. European Convention for the Protection of Human Rights and Fundamental Freedoms and its Protocols;

7. International Covenant on Civil and Political Rights and its Protocols;

8. International Covenant on Civil and Political Rights and its Protocols;

9. Convention on the Elimination of All Forms of Racial Discrimination;

10. Convention on the Elimination of All Forms of Discrimination Against Women;

11. Convention on the Rights of the Child;

12. Convention against Torture and Other Cruel, Inhumane or Degrading Treatment or Punishment;

13. Recommendation $\mathrm{CM} / \operatorname{Rec}(2008) 11$ of the Committee of Ministers to member states on the European Rules for juvenile offenders subject to sanctions or measures, 5 November 2008. 